|| ISSN(online): 2589-8698 || ISSN(print): 2589-868X ||

International Journal of Medical and Biomedical Studies

Available Online at www.ijmbs.info

NLM (National Library of Medicine ID: 101738825)

Index Copernicus Value 2019: 79.34

Original Research Article

Volume 5, Issue 1; January: 2021; Page No. 295-300

\title{
ASSESSMENT OF THE THYROID PROFILE, HS-CRP AND LIPID PROFILE IN NEWLY DETECTED
} HYPOTHYROID ADULTS: CASE-CONTROL STUDY

\author{
Dr. Amit Kumar Nirmal', Dr. Aditya Kumar², Dr. Satish Kumar ${ }^{3}$ \\ ${ }^{1}$ Junior Resident, Department of General Medicine, Nalanda Medical College and Hospital, Patna, Bihar, India \\ ${ }^{2}$ Junior Resident, Department of General Medicine, Nalanda Medical College and Hospital, Patna, Bihar, India \\ ${ }^{3}$ Associate Professor, Department of General Medicine, Nalanda Medical College and Hospital, Patna, Bihar, India
}

Article Info: Received 04 January 2021; Accepted 30 January 2021

DOI: https://doi.org/10.32553/ijmbs.v5i1.1708

Corresponding author: Dr. Satish Kumar

Conflict of interest: No conflict of interest.

\section{Abstract}

Aim: to analyse the thyroid profile, hs-CRP and lipid profile in newly detected hypothyroid adults in comparison to controls and also to compare the above parameters in subclinical and clinical hypothyroid cases.

Material and methods: The study was a cross sectional study which was carried in Nalanda Medical College and Hospital, Patna, Bihar, India from October 2019 to march 2020. Total 240 patients were divided into 2 groups. Group-1 for newly detected hypothyroid adults and Group 2 as Controls. Blood samples were collected with full aseptic precautions after obtaining informed consent. Clot activator that contains vacuum evacuated tubes for analysis of serum TSH, FT3, FT4, TC, HDL-c, LDL-c, TG, hs-CRP. Then after collection, serum samples were stored at $-20^{\circ}$ until analyzed. Anthropometric measurements for BMI, height $(\mathrm{cm})$ and body weight $(\mathrm{kg})$ were measured.

Results: The mean age of cases and controls in our study was found to be $36.12 \pm 12.21$ years and $35.87 \pm 11.06 y$ years respectively $(\mathrm{p}=0.81)$. BMI values in the study were higher in cases $(27.24 \pm 4.65 \mathrm{~kg} / \mathrm{m} 2)$ compared to controls $(25.17 \pm$ $4.37 \mathrm{~kg} / \mathrm{m} 2)$ and was statistically significant $(\mathrm{P}=0.03)$. In the study, the mean TSH levels $(15.27 \pm 9.2 \mu \mathrm{IU} / \mathrm{ml})$ of cases were high compared to controls $(3.1 \pm 0.88 \mu \mathrm{IU} / \mathrm{ml})$ and were statistically significant $(\mathrm{p}<0.001)$. The mean serum hs-CRP levels in both the study groups was within the reference range, but it was high and statistically significant in cases than in control $(\mathrm{p}=$ $0.004)$. The total cholesterol level in cases $(182.29 \pm 39.75 \mathrm{mg} / \mathrm{dl})$ and control $(184.27 \pm 28.37 \mathrm{mg} / \mathrm{dl})$ were within the reference range and there was no statistical significance $(\mathrm{p}=0.82)$. Further it was found that HDL-c in cases $(45.89 \pm 9.47 \mathrm{mg} / \mathrm{dl})$ and control $(52.87 \pm 6.7 \mathrm{mg} / \mathrm{dl})$ were found to be lower in cases compared to controls and the difference was statistically significant $(\mathrm{p}<0.001)$. The mean LDLc value in cases $(145.14 \pm 34.12 \mathrm{mg} / \mathrm{dl})$ and control $(132.05 \pm 32.14 \mathrm{mg} / \mathrm{dl})$ was high in cases and the difference was statistically significant $(\mathrm{p}=0.01)$. The triglyceride levels of cases $(159.26 \pm 49.87 \mathrm{mg} / \mathrm{dl})$ were significantly higher than that of control $(146.23 \pm 29.27 \mathrm{mg} / \mathrm{dl})$ and was statistically significant $(\mathrm{p}=0.03)$. hs $-\mathrm{CRP}$ levels were in within reference range for $92(76.67 \%)$ of cases and 109(90.83\%)controls whereas above the normal range was seen in $28(23.33 \%)$ cases and only $11(9.17 \%)$ controls. Out of $120,64.17 \%(\mathrm{n}=77)$ were subclinical hypothyroid $(\mathrm{SCH})$ and $35.83 \%(\mathrm{n}=43)$ were clinical hypothyroid $(\mathrm{CH})$ cases. There was a significant increase in serum TSH in $\mathrm{CH}(24.11 \pm 9.1 \mu \mathrm{IU} / \mathrm{ml})$ as compared to $\mathrm{SCH}(10.2 \pm 2.2 \mu \mathrm{IU} / \mathrm{ml})$. The difference was statistically significant $(\mathrm{p}<0.001)$.

Conclusion: we concluded that the hypertriglyceridemia and at risk hs-CRP levels though seen in hypothyroid cases were more prominent in $\mathrm{CH}$ cases than $\mathrm{SCH}$. Dyslipidemia and inflammatory markers were found to be increased in the cases that helped in prediction and evaluation of patients at risk of cardiovascular disease.

\section{Introduction}

Hypothyroidism is a common endocrine disorder resulting from deficiency of thyroid hormone. In the United States and other areas of adequate iodine intake, autoimmune thyroid disease (Hashimoto disease) is the most common cause of hypothyroidism; worldwide, iodine deficiency remains the foremost cause. Hypothyroidism, also called underactive thyroid or low thyroid, is a disorder of the endocrine system in which the thyroid gland does not produce enough thyroid hormone. It can cause a number of symptoms, such as poor ability to tolerate cold, a feeling of tiredness, constipation, depression, and weight gain.
Occasionally there may be swelling of the front part of the neck due to goiter. Untreated cases of hypothyroidism during pregnancy can lead to delays in growth and intellectual development in the baby or congenital iodine deficiency syndrome. ${ }^{1}$ Worldwide, too little iodine in the diet is the most common cause of hypothyroidism. Hashimoto's thyroiditis is the most common cause of hypothyroidism in countries with sufficient dietary iodine. Less common causes include previous treatment with radioactive iodine, injury to the hypothalamus or the anterior pituitary gland, certain medications, a lack of a functioning thyroid at birth, or previous thyroid surgery. The diagnosis of hypothyroidism, when suspected, can be 
confirmed with blood tests measuring thyroid-stimulating hormone (TSH) and thyroxine levels. ${ }^{2}$ Worldwide about one billion people are estimated to be iodine-deficient; however, it is unknown how often this results in hypothyroidism. In the United States, hypothyroidism occurs in $0.3-0.4 \%$ of people. Subclinical hypothyroidism, a milder form of hypothyroidism characterized by normal thyroxine levels and an elevated TSH level, is thought to occur in $4.3-8.5 \%$ of people in the United States. Hypothyroidism is more common in women than in men. ${ }^{3}$ Hypothyroidism is one of the main causes of abnormal lipid metabolism. ${ }^{4,5}$ Patients with overt hypothyroidism are at risk of hypertension, cardiovascular disease, and atherosclerosis. ${ }^{6}$ Lipid abnormalities in overt hypothyroidism includes elevated total cholesterol (TC), low density lipoprotein cholesterol (LDL-C) and triglycerides (TG). ${ }^{5}$ Although the association between subclinical hypothyroidism ( $\mathrm{SCH})$ and dyslipidemia is still controversial, changes in lipid profile in these patients have been observed in several studies.

High sensitive c-reactive protein (hs -CRP) is a marker of chronic subclinical inflammation. Increased hs -CRP levels might be a key molecule linking inflammation to oxidative stress in atherosclerosis (Singh et al) leading to $\mathrm{CV}$ risk. ${ }^{8}$ Possible role of CRP in atherogenesis might be due to enhanced expression of local endothelial cell surface adhesion molecules, endothelin-1, reduced endothelial nitric oxide bioactivity.

To explore the moderate elevations as in screening, performance of hs-CRP is recommended to better identify CRP variations. ${ }^{9,10}$ In our study we hypothesized that hypothyroidism is associated with mild dyslipidemia associated with chronic inflammatory state as measured by hs-CRP. The basic aim is to study the same in the newly detected hypothyroid adults.

\section{Material and methods}

The study was a cross sectional study which was carried in Nalanda Medical College and Hospital, Patna, Bihar, India from October 2019 to march 2020,. Total 240 patients were divided into 2 groups. in Group-1: 120 newly detected hypothyroid adults and Group 2: Controls - 120 normal healthy adults within same age group. Institutional ethical committee clearance was obtained.

\section{Inclusion criteria}

- Newly detected hypothyroid cases

\section{Exclusion criteria}

- Cardio vascular disorders,

- Diabetes Mellitus,

- kidney failure,

- Liver disorders

- Cerebrovascular accidents

- Obesity
- Infections

- Drugs

Blood samples were collected with full aseptic precautions after obtaining informed consent. Clot activator that contains vacuum evacuated tubes for analysis of serum TSH, FT3, FT4, TC, HDL-c, LDL-c, TG, hs-CRP. Then after collection, serum samples were stored at $-20^{\circ}$ until analyzed. Anthropometric measurements for BMI, height $(\mathrm{cm})$ and body weight $(\mathrm{kg})$ were measured.

Serum TSH, FT3 and FT4 by CLIA, Serum high sensitive $C$ reactive protein by Immunoturbidimetric assay and Lipid parameters analyzed in Erba EM360 autoanalyzer, Serum TG: GPO Method, HDL and LDL cholesterol by precipitation method, Total cholesterol by cholesterol oxidase - peroxidase method were investigated .

\section{Statistical analysis}

Analysis was done using SPSS version-20 software. The mean and standard deviation for quantitative variables were calculated for the study. Chi-square test, ANOVA test, students $t$ test were applied whenever necessary. Pearson correlation coefficient was obtained to find out correlation between different parameters. $\mathrm{p}$ value $<0.05$ was considered to be significant.

\section{Results}

As shown in Table 1, both cases and controls were age matched. The mean age of cases and controls in our study was found to be $36.12 \pm 12.21$ years and $35.87 \pm 11.06 y e a r s$ respectively $(\mathrm{p}=0.81)$. Approximately $90 \%$ of cases and $80 \%$ of controls were females depicting a female preponderance BMI values in the study were higher in cases $(27.24 \pm 4.65 \mathrm{~kg} / \mathrm{m} 2)$ compared to controls $(25.17 \pm$ $4.37 \mathrm{~kg} / \mathrm{m} 2)$ and was statistically significant $(\mathrm{P}=0.03)$ (Table 1) In the study, the mean TSH levels (15.27 \pm $9.2 \mu \mathrm{IU} / \mathrm{ml})$ of cases were high compared to controls $(3.1 \pm$ $0.88 \mu \mathrm{IU} / \mathrm{ml}$ ) and was statistically significant $(\mathrm{p}<0.001)$ (Table 2).The mean serum hs -CRP levels in both the study groups was within the reference range, but it was high and statistically significant in cases than in control $(\mathrm{p}=0.004)$. The total cholesterol level in cases $(182.29 \pm 39.75 \mathrm{mg} / \mathrm{dl})$ and control $(184.27 \pm 28.37 \mathrm{mg} / \mathrm{dl})$ were within the reference range and there was no statistical significance $(\mathrm{p}=0.82)$. Further it was found that HDL-c in cases $(45.89 \pm 9.47 \mathrm{mg} / \mathrm{dl})$ and control $(52.87 \pm 6.7 \mathrm{mg} / \mathrm{dl})$ were found to be lower in cases compared to controls and the difference was statistically significant $(\mathrm{p}<0.001)$. The mean LDLc value in cases $(145.14 \pm 34.12 \mathrm{mg} / \mathrm{dl})$ and control $(132.05 \pm 32.14 \mathrm{mg} / \mathrm{dl})$ was high in cases and the difference was statistically significant $(p=0.01)$. The triglyceride levels of cases $(159.26 \pm 49.87 \mathrm{mg} / \mathrm{dl})$ were significantly higher than that of control $(146.23 \pm 29.27 \mathrm{mg} / \mathrm{dl})$ and was statistically significant $(\mathrm{p}=$ 0.03). As in Table 3, hs -CRP levels were in within reference range for $92(76.67 \%)$ of cases and 
$109(90.83 \%)$ controls whereas above the normal range was seen in $28(23.33 \%)$ cases and only 11(9.17\%) controls. (Table 4)As per the Pearson's correlation, there was a significant positive correlation between serum TSH and hs CRP levels in cases $(\mathrm{r}=0.24, \mathrm{p}<0.001)$.

To analyse the condition, Hypothyroid cases $(n=120)$ in our study was divided into two groups (subclinical hypothyroid and clinical hypothyroid) based on TSH and thyroid hormone levels. Out of $120,64.17 \%(n=77)$ were subclinical hypothyroid $(\mathrm{SCH})$ and $35.83 \%(\mathrm{n}=43)$ were clinical hypothyroid $(\mathrm{CH})$ cases. A definite female preponderance was observed in the study. In Table 5, the mean age, BMI between the two groups did not differ significantly. There was a significant increase in serum $\mathrm{TSH}$ in $\mathrm{CH}(24.11 \pm 9.1 \mu \mathrm{IU} / \mathrm{ml})$ as compared to $\mathrm{SCH}(10.2$ $\pm 2.2 \mu \mathrm{IU} / \mathrm{ml})$. The difference was statistically significant ( $\mathrm{p}<0.001$ ). hs-CRP levels though high in $\mathrm{CH}$ than $\mathrm{SCH}$ were statistically insignificant $(\mathrm{p}=0.58)$. Total cholesterol value was within the reference range in both the groups $(\mathrm{CH}$ and $\mathrm{SCH})$ whereas $\mathrm{TG}$ was found to be high in $\mathrm{CH}$ compared to $\mathrm{SCH}$ and was found to be significant ( $\mathrm{p}<$ $0.001)$. There was no significant difference in HDL-c and LDL-c between the two groups ( $\mathrm{SCH} \& \mathrm{CH})$. TSH and hs$\mathrm{CRP}$ when compared between $\mathrm{SCH}, \mathrm{CH}$ and controls showed a statistically significant difference between groups with $\mathrm{p}$ value $<0.001$. (Table 6)

Table 1: Comparison with age and BMI

\begin{tabular}{llll}
\hline & Cases $\mathbf{n}=\mathbf{1 2 0}$ & Controls n=120 & P Value \\
\hline Age & $36.12 \pm 12.21$ & $35.87 \pm 11.06$ & 0.81 \\
\hline BMI $(\mathrm{Kg} / \mathrm{m} 2)$ & $27.24 \pm 4.65$ & $25.17 \pm 4.37$ & $=0.03 *$ \\
\hline
\end{tabular}

Table 2: Comparison of biochemical parameters

\begin{tabular}{llll}
\hline Parameter & Case 120 & Control $=120$ & P value \\
\hline T H $\mu$ IU/ml & $15.27 \pm 9.2$ & $3.1 \pm 0.88$ & $<0.001^{*}$ \\
\hline FT3 $\mathrm{pg} / \mathrm{ml}$ & $1.8 \pm 0.7$ & $2.0 \pm 0.8$ & $=0.38$ \\
\hline FT4 $\mathrm{ng} / \mathrm{ml}$ & $0.8 \pm 0.5$ & $0.8 \pm 0.08$ & $=1.00$ \\
\hline hs-CRP mg/l & $4.1 \pm 2.7$ & $2.9 \pm 2.4$ & $=0.004^{*}$ \\
\hline Total Cholesterol (mg/dl) & $182.29 \pm 39.75$ & $184.27 \pm 28.37$ & $=0.82$ \\
\hline HDL-c $(\mathrm{mg} / \mathrm{dl})$ & $45.89 \pm 9.47$ & $52.87 \pm 6.7$ & $<.001^{*}$ \\
\hline LDL-c(mg/dl) & $145.14 \pm 34.12$ & $132.05 \pm 32.14$ & $=0.01^{*}$ \\
\hline TG $(\mathrm{mg} / \mathrm{dl})$ & $159.26 \pm 49.87$ & $146.23 \pm 29.27$ & $=0.03^{*}$ \\
\hline
\end{tabular}

Table 3: Distribution of cases and controls according to their hs-CRP

\begin{tabular}{lll}
\hline hs-CRP mg/l $\quad<5 \mathrm{mg} / \mathrm{l}$ & $\begin{array}{l}\text { Hypothyroid Cases =120 } \\
92(76.67 \%)\end{array}$ & $\begin{array}{l}\text { Controls n=120 } \\
109(90.83 \%)\end{array}$ \\
\hline$\geq 5 \mathrm{mg} / \mathrm{l}$ & $28(23.33 \%)$ & $11(9.17 \%)$ \\
\hline Chi square value $=7.029, \mathrm{p}$ value $=0.008$ & & \\
\hline
\end{tabular}

Table 4: Pearson's correlation coefficient between TSH vs hs-CRP

\begin{tabular}{lll}
\hline Parameters & r value & P value \\
\hline TSH vs hs-CRP & $0.242^{* *}$ & $<0.001$ \\
\hline
\end{tabular}

Table 5: Comparion of various parameters among $\mathrm{CH}$ and $\mathrm{SCH}$

\begin{tabular}{llll}
\hline Parameter & CH =43 & SCH n=77 & p value \\
\hline Age $($ years $)$ & $38.12 \pm 12.11$ & $35.18 \pm 11.24$ & $=.14$ \\
\hline BMI $(\mathrm{kgm} 2)$ & $26.45 \pm 4.36$ & $26.39 \pm 5.24$ & $=.14$ \\
\hline TSH $(\mu \mathrm{IU} / \mathrm{ml})$ & $24.11 \pm 9.1$ & $10.2 \pm 2.2$ & $<.001^{*}$ \\
\hline FT3 $(\mathrm{pg} / \mathrm{ml})$ & $1.4 \pm 0.9$ & $2.5 \pm 0.5$ & $<.001 *$ \\
\hline FT4 $(\mathrm{ng} / \mathrm{ml})$ & $0.6 \pm .4$ & $1.1 \pm 0.3$ & $<.001 *$ \\
\hline hs-CRP $(\mathrm{mg} / \mathrm{l})$ & $4.4 \pm 3.7$ & $4.1 \pm 2.5$ & $=.58$ \\
\hline TC $(\mathrm{mg} / \mathrm{dl})$ & $176.4 \pm 32.6$ & $189.7 \pm 45.7$ & $=.17$ \\
\hline HDL-C $(\mathrm{mg} / \mathrm{dl})$ & $45.7 \pm 8.9$ & $46.2 \pm 8.5$ & $=.58$ \\
\hline LDL-C $(\mathrm{mg} / \mathrm{dl})$ & $151.24 \pm 36.8$ & $142.8 \pm 33.2$ & $=.36$ \\
\hline TG $(\mathrm{mg} / \mathrm{dl})$ & $107.54 \pm 20.4$ & $158.23 \pm 51.4$ & $<.001 *$ \\
\hline
\end{tabular}


Table 6: Anova of various parameters of $\mathrm{SCH}, \mathrm{CH}$ and control

\begin{tabular}{lllllll}
\hline Variales & SCH $(\mathbf{n}=\mathbf{7 7})$ & $\mathbf{C H}(\mathbf{n}=\mathbf{4 3})$ & Controls & Total & F value & P value \\
\hline T H & $10.2 \pm 2.2$ & $24.11 \pm 9.1$ & $1.92 \pm 0.89$ & $8.37 \pm 8.75$ & 317.47 & $<.001$ \\
\hline hs- CRP & $3.96 \pm 2.35$ & $4.23 \pm 3.56$ & $2.07 \pm 2.6$ & $3.06 \pm 2.92$ & 10.63 & $<.001$ \\
\hline
\end{tabular}

\section{Discussion}

Hypothyroidism is by far the most prevalent form of thyroid disorder and is more common in women. ${ }^{11}$ It is characterized by a broad clinical spectrum ranging from an asymptomatic/subclinical condition to over the state of myxoedema, end organ effects and multi organ failure. ${ }^{12}$ This study has investigated the possible association of hypothyroidism with hs-CRP, lipid profile both reportedly associated with risk of CVD. A total of 240 subjects participated in this study. Out of the total 120 subjects were newly detected hypothyroid subjects (cases) and 120 were healthy control. Both the cases and control were age matched. The mean age of cases and control was $36.12 \pm 12.21$ years and $35.87 \pm 11.06$ years respectively $(\mathrm{p}=0.81)$. Thyroid dysfunction is a common endocrine disorder with its prevalence increasing with age. About $90 \%$ of cases and $80 \%$ of control were females showing a female preponderance. Hypothyroidism is known to inflict females more than males. Devika Tayal et al in their study observed a similar female predominance with a female to male ratio of 2.86 (females 5542 vs Males 1933) A redox imbalance elicited by estrogen could be responsible for increased prevalence in female. ${ }^{13,14}$ In this study BMI was higher in hypothyroid cases. Study conducted b y Nivedita Nanda et al , Kunal B.K. ${ }^{15}$ et al reported similar observation with BMI in hypothyroidism. Thyroid hormones mediate their effects mainly through mechanism that stimulate basal metabolic rate, increase ATP expenditure, modulate adrenergic receptor number and responsiveness to catecholamines. Hypothyroid state characterized by slowing down of basal metabolic rate may be an important factor contributing to increase BMI in these cases. The mean level of serum TSH was significantly higher in cases compared to control $(15.27 \pm 9.2 \mathrm{vs} 3.1 \pm 0.88 \mu \mathrm{IU} / \mathrm{mL})$ respectively and was statistically significant $(\mathrm{p}<0.001)$. The mean serum FT3 levels $(1.8 \pm 0.7$ vs $2.0 \pm 0.8 \mathrm{pg} / \mathrm{ml}$, p $=0.38)$ and serum FT4 levels $(0.8 \pm 0.5$ vs $0.8 \pm 0.08$ $\mathrm{ng} / \mathrm{ml}, \mathrm{p}=1.0$ ) in both cases and control respectively were within the normal range (Table 2). Study done by Mohsin Shafi et al on newly detected hypothyroid patients found that mean TSH levels higher in cases as compared to control $(15.27 \pm 9.2 \mu \mathrm{IU} / \mathrm{L}$ vs $3.1 \pm 0.88)$ and was statistically significant $(\mathrm{p}<0.01){ }^{16}$ Thyroid. hormone plays a crucial role in regulation of immune system and has the potential to dampen inflammatory cytokines such as INF- $\alpha$, IL-6, IL-10. Several signs and symptoms suggest that hypothyroidism is an inflammatory state resulting from interaction of IL- 6 on TNF and IL-1 leading to increase hs CRP in this state. Recent studies found that moderate elevations of CRP correlate with future cardiovascular events justifying the use of this test to evaluate cardiovascular risk. ${ }^{17}$ This study showed that mean serum hs -CRP levels in both study groups were within reference range but the mean serum hs-CRP levels in cases was significantly higher $(\mathrm{p}=0.005)$ than in control. A significant positive correlation was also found between serum TSH and hs-CRP levels in cases $(\mathrm{r}=0.242, \mathrm{p}<0.001)$. Christcrain et al (200 3) observed an elevation in CRP levels with progressive thyroid failure and a clear association between hypothyroidism and increased hsCRP. ${ }^{18}$ Tuzcu et al , Alpaslan $\mathrm{T}$ et al ${ }^{17}$ in their studies of the association between coronary heart disease and $\mathrm{SCH}$ have reported that elevated hs -CRP levels suggest low grade inflammation predictive of CV risk in hypothyroid subjects. ${ }^{17}$ In contrary to this, a study conducted by Aksoy DY et al on women could not validate a significant difference in hs-CRP levels between hypothyroid and control. ${ }^{19}$ The interaction of IL-6 on TNF- $\alpha$ and IL-1 results in the raised CRP levels in hypothyroidism. Lack of thyroid hormones may impair the rate of CRP clearance which may be one reason in increase in serum CRP level. Similarly, slow CRP uptake in target cells might also add to this phenomenon. The low grade inflammation which may be accountable for increased risk of developing CVD in hypothyroidism. ${ }^{20}$ Thyroid disorders are known to influence lipid metabolism and other CV risk factors predominantly. Dyslipidaemia is a well-recognized association of thyroid dysfunction which should be considered in the process of evaluating and treating dyslipidemic patients. $^{21,22}$

In this study, it was found that total cholesterol values had no statistical significance but HDL-c in cases was found to be lower compared to control and the difference was statistically significant ( $\mathrm{p}<0.001)$. The mean LDL-c and triglyceride in cases were higher than control with $\mathrm{p}=$ 0.001 and $p=0.03$ respectively. Sunanda et al found that there was a strong positive association between TSH and lipid profile in hypothyroid patients and concluded that effect of hypothyroidism on the serum lipids is more pertinent in patients with higher TSH levels. ${ }^{23}$ Khan Mah et al ) also found a significant dyslipedemia i.e. significant increase in TC, LDL-c and TG levels and decrease in HDLc levels. ${ }^{24}$ Slight elevation in TSH levels, preponderance of subclinical hypothyroid subjects and shorter duration of illness (newly detected cases) might be likelihood causes of mild dyslipidemia observed in the study. In clinical hypothyroidism $(\mathrm{CH})$, a decrease in LPL activity and the clearance of TG-rich lipoproteins ${ }^{25}$ are found. Therefore $\mathrm{CH}$ patients may also present with elevated TG levels associated with increased levels of VLDL and occasionally fasting chylomicronemia ${ }^{26}$ as observed with 
hypertriglyceridemia in hypothyroid cases in the study. Many previous studies concluded that $\mathrm{CH}$ patients have elevated atherogenic and oxidative stress markers. Hence, serum TSH measurement is the essential test for diagnosis of mild thyroid failure when the peripheral thyroid hormone levels are within normal reference range. ${ }^{27}$ In this study, a low HDL levels in cases was found. Clinical studies however reported a conflicting result about HDLcholesterol plasma levels in hypothyroidism. The studies conducted by Caron et al found a reduction in HDL cholesterol and an increase in HDL after subsequent treatment with thyroxine. However, S. Valdemarssonet et al and E. Muls et al found an improvement in the mean HDL levels in the hypothyroidism with a reduction after treatment. Several proteins related with HDL metabolism are affected by thyroid hormones. ${ }^{28-30}$ The extent to which various levels of thyroid dysfunction affects $\mathrm{CV}$ event need to be debated. ${ }^{9}$ Cappola et al in their study of Cardiovascular Health Study data found that there was no relationship between $\mathrm{SCH}$ or $\mathrm{CH}$ and prevalence of atherosclerotic disease, cardiovascular mortality o $\mathrm{r}$ all causes mortality. ${ }^{31}$ For better analysis in this study, hypothyroid cases were divided into subclinical hypothyroid $(\mathrm{SCH})$ and clinical hypothyroid $(\mathrm{CH})$. Majority of the target study group was female. The mean age, BMI values between two groups did not differ significantly. The $\mathrm{CH}$ subjects has higher serum TSH levels as compared to the subjects of $\mathrm{SCH}$ which was statistically significant ( $\mathrm{P}<0.001)$. hs -CRP levels were found to be at risk level and was comparable in both $\mathrm{CH}$ and $\mathrm{SCH}$ but was statistically insignificant $(\mathrm{p}=0.58)$. Many studies have shown that high levels hsCRP in women with $\mathrm{SCH}$ correlated with parameters of obesity which emphasizes the role of body weight in inflammation and may consider as an additional risk factor for the development of atherosclerosis and CVD. ${ }^{32,33}$ Total cholesterol value was found to be within reference range in both the groups $(\mathrm{CH}$ and $\mathrm{SCH}$ ) but $\mathrm{TG}$ value was found to be high in $\mathrm{CH}$ as compared to $\mathrm{SCH}$ which was found to be statistically significant $(\mathrm{p}<0.001)$. There was no significant differences in HDL-c, LDL-c between two groups. The mean values of serum TSH and hs-CRP were higher in $\mathrm{CH}$ as compared to $\mathrm{SCH}$ and controls. It was observed that the difference was statistically significant $(\mathrm{p}<0.001)$. Studies conducted by Biondi and Cooper have shown that $\mathrm{SCH}$ is associated with variable and inconsistent changes in above mentioned parameters in contradictory to $\mathrm{CH}$ in which significant changes are normally found. ${ }^{34}$

\section{Conclusion}

We concluded that the hypertriglyceridemia and at risk hsCRP levels though seen in hypothyroid cases were more prominent in $\mathrm{CH}$ cases than $\mathrm{SCH}$. Dyslipidemia and inflammatory markers were found to be increased in the cases that helped in prediction and evaluation of patients at risk of cardiovascular disease.

\section{Reference}

1. Preedy Victor. Comprehensive Handbook of Iodine Nutritional, Biochemical, Pathological and Therapeutic Aspects. Burlington: Elsevier, 2009:616.

2. "Hypothyroidism". National Institute of Diabetes and Digestive and Kidney Diseases. March 2013. Archived from the original on 2016.

3. Mosby's Medical Dictionary(9ed.). Elsevier Health Sciences.2013:887.

4. Pucci E, Chiovato L, Pinchera A. Thyroid and lipid metabolism. Int J Obesity. 2000;24:S109-12.

5. Rizos CV, Elisaf MS, Liberopoulos EN. Effects of thyroid dysfunction on lipid profile. Open Cardiovasc Med J. 2011;5:76-84.

6. Bell RJ, Rivera-Woll L, Davison SL, Topliss DJ, Donath S, Davis SR. Well-being, health-related quality of life and cardiovascular disease risk profile in women with subclinical thyroid disease: a community-based study. Clin Endocrinol (Oxf). 2007;66(4):548-56.

7. Duntas LH. Thyroid disease and lipids. Thyroid. 2002;12(4):287-93

8. Singh S, Dey PS. Serum lipids, tHcy, hs-CRP, MDA and PON-1 levels in $\mathrm{SCH}$ and overt hypothyroidism: effect of treatment. Acta Bomed. 2014;85(2):127-134.

9. Shishehbor HM, L BD, Eric J. Using C-reactive protein to assess cardiovascular disease risk. Leveland Clin J Med. 2009;70(7):634- 640.

10. Omair Y, Mohanty DB, Martin SS. High-Sensitivity C-Reactive Protein and Cardiovascular Disease. J Am Cardiol. 2013;62(5):397- 408

11. Dhok JA, Adole SP, Puppalwar VP. Status of Thyroid disorders at Acharya Vinobha Bhave Rural Hospital, Sawangi (Meghe), Wardha, India. Thyroid Res Pract. 2015;12(2):62-66.

12. Gopalakrishnan AU, Kalra S, Sahay K. Prevalence of hypothyroidism in adults: An epidemiological study in eight cities of India. Indian Journal Endocrinol Metab. 2013;17(4):647-652.

13. Tayal D, Chawla R, Arora S. Dynamic Changes in Biochemical Markers of Renal Function with Thyroid Status - A Study in Indian Population. Internet J Med . 2009;4(2):36-41.

14. Fortunato RS, Ferreira AC, Hecht F. Sexual dimorphism and thyroid dysfunction: a matter of oxidative stress? J Endocrinol. 2014;221(2):31-40.

15. Nivedita N, Zachariah B, Hamide A. Insulin Resistance Among Hypothyroid Patients In India. Asian J Biochem. 2012;7(3):151-157.

16. Mohsin S, Azim W, Nawaz MA. Effect of Hypothyroidism On Lipid Profile In Asymptomatic Newly Diagnosed Patients. Biomedica. 2013;29:1215.

17. Tuzcu A, Bahceci M, Gokalp D. Subclinical Hupothyroidism May Be Associated With Elevated High Sensitive C Reactive Protein (Low Grade 
Inflammation) And Fasting Hyperinsulinemia. 2005;52(1):89- 94

18. Christ-Crain. Elevated C-reactive protein and homocysteine values: Cardiovascular risk factors in hypothyroidism? A cross-sectional and double-blind, placebo-controlled trial. Atheroscler. 2002;166:379386.

19. Dugyu AY, Cinar N, Alya H. Serum Resistin and High Sensitive CRP Levels in Patients with Subclinical Hypothyroidism Before and after LThyroxine Therapy. 2013;19:210-215.

20. Serafino P, Emiliano L, Gaetano. Effects of Thyroid Hormone on the Cardiovascular System. J Clin Endocrinol Metab. 2004;p. 31-50

21. Upadhayay Kant R. Emerging Risk Biomarkers in Cardiovascular Diseases and Disorders. Journal of Lipids. 2015;p. 33-33. Article ID 971453.

22. Abd lazeem Siddeg. Evaluation of serum lipid profile in Sudanese patient with thyroid Dysfunction. J Applied Med Sci. 2015;3(6A):2178-2182.

23. Aml Mohamed Nada. Effect of treatment of overt hypothyroidism on insulin resistance. World J Diabetes. 2013;15(4):157-161.

24. MAH K, Ishaque M, Hoque M, Fariduddin M, Mollah FH, Arslan MI. Lipid Profile in Hypothyroid Patients: A Cross Sectional Study. Bangladesh J. 2013;24(1).

25. Lee WY, Suh JY, Rhee EJ, Park JS, Sung KC, Kim SW. Plasma CRP, apolipoprotein A-1, apolipoprotein $\mathrm{B}$ and $\mathrm{Lp}$ (a) levels according to thyroid function status. Arch Med Res. 2004;35:540-545.
26. Al-Tonsi AA, Gayoum AAA, Saad M. The secondary dyslipidemia and deranged serum phosphate concentration in thyroid disorders. Exp Mol Pathol. 2004;76:182-187.

27. Vehab F. Subclinical Hypothyroidism: An Update For Primary Care Physicians. Mayo Clinic Proceedings. 2009;84(1):65-71.

28. Feng X, Jiang Y, Meltzer P. Thyroid hormone regulation of hepatic genes in vivo detected by complementary DNA microarray. Molec Endocrinol. 2000;14(7):947-955.

29. Franco M. Pleiotropic Effects of thyroid Hormones: Learning from Hypothyroidism. J Thyroid Res. 2011;p. 17.

30. Duntas LH. Thyroid Disease and lipids. Thyroid. 2002;12(4):287-293.

31. Cappola AR, Landenson PW. Hypothyroidism And Atherosclerosis. J Clin Endocrinol Metab. 2003;88:2438-2444.

32. Marrow DA, Ridke PM. Long-term effects of pravastatin on plasma concentration of C-reactive protein. The Cholesterol and Recurrent Events (CARE) Investigators. Circ. 1999;100:230-235.

33. Nikkila EA, Kekki M. Plasma triglyceride metabolism in thyroiddisease. $\mathrm{J}$ Clin Invest. 1972;51:2103-2114.

34. Biondi B, David CS, . The Clinical Significance of Subclinical Thyroid Dysfunction. Endocr Rev.

35. 2008;29(1):76-131 